Ekonomica Sharia: Jurnal Pemikiran dan Pengembangan Ekonomi Syariah Volume 6Nomor 1 Edisi Agustus $2020 \mid 1$

\title{
PENGARUH KUALITAS AKTIVA PRODUKTIF DAN NET PERFORMING FINANCING (NPF) TERHADAP NET OPERATING MARGIN (NOM) BANK UMUM SYARIAH DAN UNIT USAHA SYARIAH PERIODE JUNI 2014 - MARET 2020
}

\author{
Aris Munandar \\ Fakultas Ekonomi Universitas IGM Palembang \\ Email: arismunandar@uigm.ac.id
}

\begin{abstract}
Net Operating Margin (NOM) is a ratio that is needed to improve the ability of banks to manage their entire productivity in order to produce a higher net. While Non-Performing Financing (NPF) is an indicator of credit risk (financing) of Islamic banks. Banks with high NPFs are less effective. Consider a bank with a lower NPF, more efficient. This study aims to look at the effect of Earning Asset Quality and Non-Performing Financing (NPF) on Net Operating Margin (NOM) in Sharia Commercial Banks and Sharia Business Units. The data used in this study is monthly coherent data from the period June 2014 to March 2020. Technical data analysis uses multiple regression models that are processed with IBM SPSS V.26.0. The results showed that the Earning Assets Quality (KAP) had a significant negative effect on the Net Operating Margin (NOM) variable with a KAP coefficient of -0.017 with a significance level of 0.610. Net Performing Financing (NPF) has a significant negative effect on the Net Operating Margin (NOM) variable with a NPF coefficient of -0.482 with a significance level of 0,000. F test results (simultaneous) Earning Asset Quality (KAP) and Net Performing Financing (NPF) have a significant effect on the Net Operating Margin (NOM) of BUS and UUS. Test the coefficient of determination (Adjusted $R$ Square) of 0.732 or of $73.2 \%$. This shows that Earning Asset Quality (KAP) and Net Performance Financing (NPF) contributed $73.2 \%$ to Net Operating Margin (NOM). While the remaining $26.8 \%$ was placed by other variables outside this study.
\end{abstract}

Keywords: NOM, NPF, Rice Productive Assets, Al-Misbah and Market Mechanisms

\begin{abstract}
Abstrak
Net Operating Margin (NOM) merupakan suatu rasio yang dijadikan patokan untuk mengetahui seberapa besar kemampuan bank dalam menggelola seluruh aktiva produktifnya agar bisa menghasilkan penghasilan netto yang lebih tinggi. Sedangkan Non Performing Financing (NPF) merupakan indikator dari risiko kredit (pembiayaan) bank syariah. Bank dengan NPF yang tinggi cenderung kurang efisien. Sebaliknya bank dengan NPF yang rendah cenderung lebih efisien. Penelitian ini bertujuan untuk melihat Pengaruh Kualitas Aktiva Produktif dan Non Performing Financing (NPF) Terhadap Net Operating Margin (NOM) pada Bank Umum Syariah dan Unit Usaha Syariah. Data yang digunakan dalam penelitian ini adalah data runtut bulanan dari periode Juni 2014 sampai dengan Maret 2020. Teknis analisis data menggunakan model regresi berganda yang diolah dengan IBM SPSS V.26.0. Hasil penelitian menunjukkan bahwa Kualitas Aktiva Produktif (KAP) berpengaruh negatif tidak signifikan terhadap variabel Net Operating Margin (NOM) dengan nilai koefisien KAP sebesar -0.017 dengan tingkat signifikansi sebesar 0.610. Net Performing Financing (NPF) berpengaruh negatif signifikan terhadap variabel Net Operating Margin (NOM) dengan nilai
\end{abstract}




\section{2 | Aris Munandar, Pengatuh Aktiva Produktif dan Net Performing Financing (NPF)....}

koefisien NPF sebesar - 0.482 dengan tingkat signifikansi 0.000. Hasil uji F (simultan) Kualitas Aktiva Produktif (KAP) dan Net Performing Financing (NPF) berpengaruh signifikan terhadap Net Operating Margin (NOM) BUS dan UUS. Uji koefisien determinasi (Adjusted R Square) sebesar 0.732 atau sebesar 73,2\%. Hal ini menunjukkan bahwa Kualitas Aktiva Produktif (KAP) dan Net Performing Financing (NPF) berkontribusi sebesar 73,2\% terhadap Net Operating Margin (NOM). Sedangkan sisanya sebesar 26,8\% dipengaruhi oleh variabel lain diluar penelitian ini.

Kata Kunci: NOM, NPF, Aktiva Produktif Rice, Al-Misbah and Market Mechanisms

\section{DASAR PEMIKIRAN}

Indonesia merupakan salah satu negara dengan penduduk mayoritas muslim terbesar dunia. Sehingga Indonesia bisa menjadi negara yang sangat berpotensi dalam perkembangan keuangan syariah. Saat ini perkembangan bank-bank yang kegiatan operasionalnya menggunakan prinsip Syariah tumbuh pesat. Pada tahun 1992 berdirilah Bank Umum Syariah pertama di Indonesia, yaitu Bank Muamalat Indonesia (BMI).

Sistem perbankan konvensional dan Syariah memiliki aspek yang berbeda, perbedaan yang utama dari sisi kepatuhan terhadap nilai-nilai syariah (shariah compliance). Nilai inilah yang membuat perbankan syariah lebih unggul dibandingkan dengan operasional perbankan konvensional, hal ini disebabkan perbankan syariah menjamin penerapan nilai-nilai keadilan bagi pelaku-pelaku ekonomi, dan tentunya terpenuhinya nilai-nilai syariah. Sistem bagi hasil pada Bank Umum Syariah dapat memberikan manfaat yang berkeadilan bagi semua pihak, baik itu bagi pemilik modal, pemilik dana sebagai deposan, pengusaha sebagai debitur maupun dari pihak bank itu sendiri sebagai pengelola.

Kondisi keuangan bank syariah dapat dikatakan baik atau buruk dapat dilihat dari likuiditas yang dimilikinya. Likuiditas merupakan rasio yang dapat menunjukkan kemampuan bank syariah dalam memenuhi kewajiban jangka pendeknya yang jatuh tempo. Selain likuiditas, Rentabilitas tidak kalah penting dalam menilai kondisi sebuah perbankan, rentabilitas merupakan salah satu faktor penting yang selalu diperhatikan dalam menjalankan suatu usaha. Bank harus paham terhadap permasalahan yang berkaitan dengan kegiatan perbankan dalam hal menggelola keuangan yang akan disalurkan kepada nasabah, sehingga bank mendapatkan margin dari nasabah tersebut. 
Ekonomica Sharia: Jurnal Pemikiran dan Pengembangan Ekonomi Syariah Volume 6Nomor 1 Edisi Agustus $2020 \mid 3$

Net Operating Margin (NOM) merupakan salah satu hal yang harus mendapat perhatian serius dari perbankan.

Net Operating Margin (NOM) dapat menggambarkan seberapa besar bank memiliki kemampuan dalam menggelola seluruh aset produktifnya agar dapat menciptakan penghasilan bersih yang lebih tinggi. Net Operating Margin (NOM) linier dengan pendapatan margin yang diterima oleh perbankan. Semakin tinggi pendapatan margin yang didapat perbankan maka akan semakin besar pula rasio atau NOM perbankan tersebut, artinya bank sudah bekerja dengan efisien untuk menghasilkan pendapatan yang lebih tinggi. Dengan rasio yang tinggi dapat mempermudah perbankan untuk terhindar dari berbagai masalah perbankan.

Pada saat ini ada dua metode utama yang dijalankan oleh perbankan syariah dalam menyalurkan pembiayaannya, pertama pembiayaan yang berprinsip jual beli dan kedua pembiayaan yang berprinsip pada bagi hasil. Murabahah merupakan suatu wujud jual beli tertentu disaat penjual memberitahukan biaya memperoleh barang, yaitu harga barang dan biaya - biaya lainnya yang dibebankan untuk mendapatkan barang tersebut, serta tingkat keuntungan (margin) yang diharapkan (Ascarya, 2015: 81). Ketika kredit disalurkan oleh perbankan, kemungkinan besar perbankan akan dihadapkan pada risiko gagal bayar atau kredit macet. Non Performing Financing (NPF) merupakan salah satu indikator dari risiko kredit (pembiayaan) pada perbankan syariah. Bank dengan tingkat Non Performing Financing (NPF) yang tinggi pengelolaannya cenderung tidak efisien. Sebaliknya perbankan dengan tingkat Non Performing Financing (NPF) yang cenderung rendah dianggap lebih efisien. Perbankan dengan tingkat Non Performing Financing (NPF) yang rendah tentu memiliki kemampuan menyalurkan dananya kepada nasabah lebih luas, sehingga tingkat profitabilitasnya akan semakin tinggi (Almunawwaroh \& Marliana, 2018).

Selain itu bank syariah juga harus mampu menjaga kualitas aset produktifnya agar dapat tercapainya target pendapatan atau laba yang diharapkan. Penurunan kualitas dan nilai aset merupakan sumber kerugian terbesar bagi perbankan. Kualitas aset adalah komponen yang sangat penting dari profil kredit bank. Beberapa pendapat menyatakan bahwa kualitas aset produktif yang buruk telah menjadi bukti penyebab kegagalan 


\section{4 | Aris Munandar, Pengatuh Aktiva Produktif dan Net Performing Financing (NPF)....}

perbankan, meskipun sebab yang jelas mungkin tidak cukup likuiditas atau modal. (Silvia, 2017).

Mengingat kualitas aset produktif adalah permasalahan yang penting bagi perbankan untuk mengantisipasi perbankan dari kebangkrutan. Dan juga risiko bank pada umumnya berasal dari kredit macet. Maka perbankan harus mampu menunjukan tingkat kesehatan yang baik, karena perbankan merupakan pihak intermediasi dalam meningkatkan kepercayaan masyarakat kepada bank dalam mengelolah dana masyarakat.

\section{TINJAUAN PUSTAKA}

Salah satu faktor yang penting untuk membuktikan tingkat efektifitas dan efisiensi perbankan dalam pengelolaan usaha guna mencapai tujuan ialah tingkat Kesehatan bank. Pengertian dari Tingkat Kesehatan Bank antara lain sebagai berikut: Tingkat Kesehatan Bank seperti hasil perhitungan evaluasi kualitatif dari berbagai bidang yang berdampak pada situasi atau prestasi suatu bank mencakup pengukuran faktor permodalan, kualitas aset, manajemen, profitabilitas, likuiditas, dan sensitivitas terhadap risiko market. (Taswan, 2010:537)

Kesehatan perbankan bisa dimaknai sebagai kapabilitas suatu bank dalam melaksanakan aktivitas usaha perbankan secara normal dan bisa memenuhi seluruh fungsinya dengan baik berdasarkan cara yang sesuai dengan peraturan perbankan yang berlaku. Aktivitas tersebut mencakup:

1. Kapabilitas dalam mengumpulkan dana dari masyarakat, lembaga lain, atau dari modal sendiri.

2. Kapabilitas dalam pengelolaan dana

3. Kapabilitas dalam penyaluran dana ke masyarakat

4. Kapabilitas dalam membayar kewajiban kepada masyarakat, karyawan, pemilik modal, dan pihak lain

5. Pemenuhan peraturan perbankan yang berlaku (Sigit Triandaru dan Totok Budisantoso, 2008:52). 
Ekonomica Sharia: Jurnal Pemikiran dan Pengembangan Ekonomi Syariah Volume 6Nomor 1 Edisi Agustus $2020 \mid 5$

Perhitungan tingkat kesehatan perbankan syariah bisa dilakukan berdasarkan sistem peringkat CAMELS, yaitu Penanaman Modal (capital), kekayaan (asset), kemampuan manajemen (management), kinerja keuangan (earning), likuiditas (liquidity) dan kepekaan terhadap ancaman atau risiko. Ketetapan RBBR akan memperkirakan tata kelola perusahaan, profil risiko, investasi serta rentabilitas yang berkaitan dengan permodalan.

Kebijakan OJK No. 8/POJK.03/2014 mengenai tata cara menilai tingkat Kesehatan Bank Umum Syariah dan Unit Usaha Syariah, Otoritas Jasa Keuangan (OJK) telah melaksanakan penilaian kedalam lima peringkat komposit (PK). Peringkat (PK) pertama menggambarkan bank dengan kondisi yang sangat sehat, sedangkan keadaan bank yang tidak sehat di beri peringkat (PK) 5 .

Aktiva Produktif adalah investasi dana BPR dalam bentuk kurs rupiah guna mendapatkan pendapatan, dalam wujud Kredit, Sertifikat Bank Indonesia, dan Penempatan Dana Antar Bank" (PBI No 9/18/PBI/2006).

Kualitas Aktiva Produktif merupakan pendanaan pihak bank dalam mata rupiah atau valuta asing bisa berbentuk surat berharga, piutang, pembiayaan, penempatan dan penyertaan modal, komitmen dan kontijensi, serta penyertaan modal sementara pada transaksi rekening administratif. Aktiva produktif adalah sumber pendapatan bank, sebagai sumber pendapatan pasti memiliki risiko terbesar. Potensi kerugian atas risiko tersebut dapat diantisipasi dengan cara membentuk Penyisihan Penghapusan Aktiva Produktif (PPAP) yang berupa cadangan umum dan cadangan khusus sehingga dapat menutup kemungkinan kerugian yang akan terjadi (Taswan, 2005:245).

Penilaian Kualitas Aktiva Produktif berdasarkan ketentuan perbankan di Indonesia berdasarkan pada 2 (dua) rasio antara lain:

1. Rasio Kualitas Aktiva Produktif

Rasio Kualitas Aktiva Produktif (KAP) merupakan rasio yang sering digunakan untuk menghitung komparasi antara Aktiva Produktif yang Diklasifikasikan (APYD) berdasarkan ketentuan yang berlaku terhadap total Aktiva Produkif (AP), dengan rumus: 


$$
\mathrm{KAP}=\frac{\mathrm{APYD}}{\text { Aktiva Produktif }} \mathrm{X} 100 \%
$$

\section{Rasio Penyisihan Penghapusan Aktiva Produktif (PPAP)}

Rasio PPAP berfungsi untuk memperkirakan perbandingan antara Penyisihan

Penghapusan Aktiva Produktif yang Dibentuk (PPAPYD) terhadap Penyisihan Penghapusan Aktiva Produktif yang Wajib Dibentuk (PPAPWD), dengan rumus:

$$
\text { Rasio PPAP }=\frac{\text { PPAP yang dibentuk }}{\text { PPAP yang wajib dibentuk }} \mathrm{X} 100 \%
$$

Non Performing Financing (NPF) ialah pinjaman atau kredit yang di kategorikan sebagai kredit kurang lancar atau diragukan bahkan macet. Tugas Bank Indonesia yaitu mengelola dan menjaga sistem perbankan dengan baik sehingga dipercaya serta bertujuan untuk menjaga stabilitas perekonomian. Bank Indonesia (BI) selaku Bank sentral dan juga sebagai pengawas perbankan di Indonesia terus memberikan ketentuan tentang ukuran penilaian tingkat kesehatan Bank. Salah satu peraturan Bank Indonesia (BI) ialah Non Performing Financing (NPF) Bank harus kurang dari 5\%.

Non Performing Financing (NPF) Gross ialah komparasi antara jumlah pinjaman yang diberikan dengan tingkat kolektibilitas 3 sampai 5 (kurang lancar, diragukan dan macet) dibandingkan terhadap total pinjaman yang diberikan oleh Bank. sedangkan Non Performing Financing (NPF) Net merupakan komparasi antara sejumlah pinjaman yang diberikan dengan tingkat kolektibilitas 3 sampai 5 (Kurang lancar, diragukan dan Macet) dikurangi Penyisihan Penghapusan Aktiva Produktif (PPAP) tingkat kolektibilitas 3 sampai dengan 5 (Kurang lancar, diragukan dan macet) dibandingkan dengan total pinjaman yang diberikan oleh Bank.

Net Operating Margin merupakan rasio utama Rentabilitas pada bank syariah untuk mengetahui kemampuan aktiva produktif dalam menghasilkan laba. Net Operating Margin juga dapat diartikan rasio rentabilitas untuk mengetahui kemampuan aktiva produktif dalam menghasilkan laba melalui perbandingan pendapatan operasional dan beban operasional dengan rata-rata aktiva produktif. 
Ekonomica Sharia: Jurnal Pemikiran dan Pengembangan Ekonomi Syariah Volume 6Nomor 1 Edisi Agustus $2020 \mid 7$

Net Operating Margin dapat dilihat dari dua perspektif. Jika dilihat dari perspektif pertama yaitu dari sisi sifat kompetitif bank dan sisi rentabilitas, margin yang kecil mengindikasikan sistem perbankan yang kompetitif dengan biaya intermediasi yang rendah, namun disisi rentabilitas margin yang tinggi menggambarkan stabilitas dari sistem perbankan ini dilatarbelakangi bank yang dapat menambahkan margin yang tinggi ke dalam rentabilitas dan modal sehingga dapat melindungi dari resiko.

Rumus menghitung NOM sebagai berikut:

$$
\mathrm{NOM}=\frac{(\mathrm{PO}-\mathrm{DBH})-\mathrm{BO}}{\text { Rata }- \text { rata AP }}
$$

Penelitian ini bertujuan untuk mengetahui pengaruh Pengaruh Kualitas Aktiva Produktif dan Non Performing Financing (NPF) terhadap Net Operating Margin (NOM), maka dirumuskan hipotesis sebagai berikut:

$\mathrm{H}_{1}=$ Secara simultan Kualitas Aktiva Produktif dan Non Performing Financing (NPF) berpengaruh Net Operating Margin (NOM).

$\mathrm{H}_{2}=$ Kualitas Aktiva Produktif berpengaruh Net Operating Margin (NOM).

$\mathrm{H}_{3}=$ Non Performing Financing (NPF) berpengaruh Net Operating Margin (NOM).

\section{METODE PENELITIAN}

Penelitian ini memakai pendekatan statistik parametrik. Dalam penelitian ini, peneliti akan menghitung seberapa besar pengaruh KAP dan NPF terhadap Net Operating Margin (NOM). Penelitian dibatasi dengan menganalisa dari laporan Statistik Perbankan Syariah di Indonesia dalam rentang waktu Juli 2014 sampai dengan Maret 2020 yang tercantum dalam situs Otoritas Jasa Keuangan. Penggunaan waktu tersebut didasarkan dari ketersediaan data pada laporan Statistik Perbankan Syariah yang dikeluarkan oleh OJK.

Analisis data dilakukan dengan menggunakan regresi linear berganda yang bertujuan untuk menguji dan menganalisis, baik secara parsial maupun simultan pengaruh KAP dan NPF terhadap NOM. 


\section{8 | Aris Munandar, Pengatuh Aktiva Produktif dan Net Performing Financing (NPF)....}

\section{PEMBAHASAN}

\section{Tabel 1}

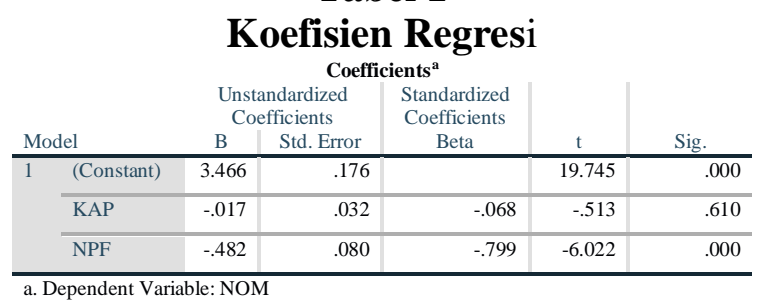

Dari tabel di atas maka dapat disusun persamaan regresi linier berganda sebagai berikut:

$\mathrm{NOM}=3,466-0,017 \mathrm{KAP}-0,482 \mathrm{NPF}+\mathrm{e}$

koefisien regresi KAP adalah sebesar -0,017 yang berarti bahwa setiap peningkatan $1 \%$ satuan KAP akan menurunkan NOM sebesar $0.017 \%$ dengan asumsi kondisi variabel bebas lain tetap.

koefisien regresi NPF adalah sebesar -0.482 yang berarti bahwa setiap peningkatan $1 \%$ satuan NPF akan menurunkan NOM sebesar $0.482 \%$ dengan asumsi kondisi variabel bebas lain tetap.

\begin{tabular}{|c|c|c|c|c|c|c|}
\hline & & & \multicolumn{2}{|c|}{ Uji F } & \multirow[b]{2}{*}{$F$} & \multirow[b]{2}{*}{ Sig. } \\
\hline \multicolumn{2}{|c|}{ Model } & $\begin{array}{l}\text { Sum of } \\
\text { Squares }\end{array}$ & df & $\begin{array}{l}\text { Mean } \\
\text { Square }\end{array}$ & & \\
\hline 1 & Regression & 11.942 & 2 & 5.971 & 95.078 & $.000^{\mathrm{b}}$ \\
\hline & Residual & 4.208 & 67 & .063 & & \\
\hline & Total & 16.150 & 69 & & & \\
\hline
\end{tabular}

Dasar pengambilan keputusan uji $\mathrm{F}$ dilakukan dengan cara membandingkan nilai $\mathrm{F}$ hitung dengan nilai F tabel. Variabel KAP, dan NPF dinyatakan berpengaruh secara simultan terhadap NOM perbankan syariah apabila nilai $\mathrm{F}$ hitung lebih besar dari nilai $\mathrm{F}$ tabel. Berikut ini adalah pengambilan keputusan hipotesis yang akan diuji: $\mathrm{H}_{\mathrm{o}}: \beta=0$, KAP dan NPF tidak berpengaruh signifikan secara simultan terhadap NOM. $\mathrm{H}_{1}: \beta \neq 0$, KAP dan NPF berpengaruh signifikan secara simultan terhadap NOM.

Berdasarkan tabel 2 di atas diperoleh hasil nilai F-Statistik sebesar 95,078 dengan nilai probabilitas sebesar 0.000. Sedangkan nilai $\mathrm{F}$ tabel dengan tingkat signifikansi 5\% dapat diperoleh melalui perhitungan berikut:

- $\mathrm{df}_{1}=($ jumlah variabel -1$)=3-1=2$

- $\mathrm{df}_{2}=($ jumlah data - jumlah variabel independen -$) \mathrm{df}_{2}=70-2-1=67$. 
Ekonomica Sharia: Jurnal Pemikiran dan Pengembangan Ekonomi Syariah Volume 6Nomor 1 Edisi Agustus 2020 | 9

Berdasarkan perhitungan tersebut, maka diperoleh nilai F tabel sebesar 3,134. Nilai F hitung yang ditunjukkan oleh tabel 5.5 lebih besar dari nilai F tabel, yaitu 95,078 > 3,134. Dengan begitu dapat disimpulkan bahwa $\mathrm{H}_{1}$ diterima dan Ho ditolak, yang berarti KAP dan NPF secara simultan memiliki pengaruh terhadap NOM Bank Umum Syariah dan Unit Usaha Syariah.

Tarif signifikansi $(\alpha)$ yang digunakan oleh peneliti, yaitu 0,05 . Pada table 2 , nilai sig sebesar 0.000. Oleh karena nilai sig lebih kecil dari taraf signifikansi $(\alpha) 0,05$, maka dapat disimpulkan bahwa $\mathrm{H}_{1}$ diterima dan Ho ditolak. Hasil analisis menunjukkan bahwa variabel KAP dan NPF secara simultan berpengaruh signifikan terhadap variabel NOM Bank Umum Syariah dan Unit Usaha Syariah.

Berdasarkan tabel 1. diatas, KAP memiliki t hitung sebesar 0.513 dengan tingkat signifikansi 0.610. Karena nilai $\mathrm{t}$ hitung lebih kecil daripada nilai t tabel $(0.513<$ 1,995), maka variabel KAP dinyatakan tidak berpengaruh secara parsial terhadap NOM. Kemudian, diketahui pula bahwa variabel KAP memiliki nilai signifikansi 0.610, lebih besar dari $0,05(0.610>0.05)$ maka dapat disimpulkan bahwa cukup bukti untuk menerima $\mathrm{H}_{\mathrm{o}}$ dan menolak $\mathrm{H}_{1}$. Jadi, variabel KAP secara parsial tidak berpengaruh signifikan terhadap variabel NOM.

Berdasarkan tabel diatas, NPF memiliki t hitung sebesar 6.022 dengan tingkat signifikansi 0.000. Karena nilai t hitung lebih besar daripada nilai t tabel (6.022 > 1,995), maka variabel NPF dinyatakan berpengaruh secara parsial terhadap NOM. Kemudian, diketahui pula bahwa variabel NPF memiliki nilai signifikansi 0.000, lebih kecil dari $0,05(0.000<0.05)$ maka dapat disimpulkan bahwa cukup bukti untuk menolak $\mathrm{H}_{\mathrm{o} 1}$ dan menerima $\mathrm{H}_{1}$. Jadi, variabel NPF secara parsial berpengaruh signifikan terhadap variabel NOM.

\section{Tabel 3}

\section{Hasil Uji Koefisien Determinasi}

\begin{tabular}{|c|c|c|c|c|c|}
\hline \multirow[b]{2}{*}{ Model } & \multicolumn{5}{|c|}{ Model Summary ${ }^{b}$} \\
\hline & $\mathrm{R}$ & R Square & $\begin{array}{l}\text { Adjusted } \\
\text { R Square }\end{array}$ & $\begin{array}{l}\text { Std. Error of } \\
\text { the Estimate }\end{array}$ & $\begin{array}{l}\text { Durbin- } \\
\text { Watson }\end{array}$ \\
\hline 1 & $.860^{\mathrm{a}}$ & .739 & .732 & .25060 & 1.039 \\
\hline
\end{tabular}

Berdasarkan table 3 dapat dilihat nilai koefisien determinan (Adjusted R Square) sebesar 0.732 atau sebesar 73,2\%. Hal ini menunjukkan bahwa KAP dan NPF 
10 Aris Munandar, Pengatuh Aktiva Produktif dan Net Performing Financing (NPF).... berkontribusi sebesar $73,2 \%$ terhadap NOM. Sedangkan sisanya sebesar $26,8 \%$ dipengaruhi oleh variabel lain yang tidak diteliti dalam penelitian ini.

\section{SIMPULAN}

Berdasarkan hasil uji $\mathrm{F}$ (simultan) dapat dilihat bahwa variabel independen yang digunakan pada penelitian ini secara bersama-sama (simultan) berpengaruh signifikan terhadap variabel dependen, yaitu KAP dan NPF secara simultan berpengaruh signifikan terhadap NOM BUS dan UUS. Ini dikarenakan hasil nilai sig pada tabel ANOVA dengan tarif signifikansi $(\alpha)$ yang digunakan peneliti lebih kecil yaitu $0.000<0,05$. Dan Berdasarkan uji koefisien determinasi (Adjusted $R$ Square) sebesar 0.732 atau sebesar $73,2 \%$. Hal ini menunjukkan bahwa KAP dan NPF berkontribusi sebesar 73,2\% terhadap NOM. Sedangkan sisanya sebesar 26,8\% dipengaruhi oleh variabel lain diluar penelitian ini.

Kualitas Aktiva Produktif (KAP) secara parsial tidak berpengaruh signifikan terhadap variabel NOM dan memiliki hubungan berbanding terbalik (negatif) terhadap variabel NOM. Nilai koefisien KAP sebesar (-) 0.017 dengan tingkat signifikansi 0.610. Net Performing Financing (NPF) secara parsial berpengaruh signifikan terhadap variabel NOM dan memiliki hubungan berbanding terbalik (negatif) terhadap variabel NOM. Nilai koefisien NPF sebesar -0.482 dengan tingkat signifikansi 0.000. 
Ekonomica Sharia: Jurnal Pemikiran dan Pengembangan Ekonomi Syariah Volume 6Nomor 1 Edisi Agustus $2020 \mid 11$

\section{SARAN}

Bagi Akademisi, hasil penelitian ini dapat dijadikan sebagai acuan untuk meneliti lebih jauh lagi mengenai Rentabilitas khususnya yang diproxykan oleh Net Operating Margin (NOM), karena dalam penelitian ini hanya menggunakan 2 variabel independen. Disarankan untuk peneliti selanjutnya memasukkan variabel lain seperti Inflasi, persaingan antar perbankan syariah dan konvensional dan suku bunga BI.

Bagi para praktisi perbankan syariah, dari hasil penelitian bahwa perbankan syariah harus lebih memperhatikan NPF karena memiliki hubungan signifikan dalam mempengaruhi tingkat rentabilitas (NOM) BUS dan UUS. Untuk membantu mendorong optimalisasi rentabilitas, bank dapat lebih meningkatkan porsi penyaluran dana pada sektor produktif daripada sektor konsumtif yang memiliki tingkat resiko yang lebih tinggi. 


\section{DAFTAR PUSTAKA}

Almunawwaroh, M., \& Marliana, R. (2018). Pengaruh CAR, NPF Dan FDR Terhadap Profitabilitas Bank Syariah Di Indonesia. Amwaluna: Jurnal Ekonomi Dan Keuangan Syariah, 2(1), 1-17. https://doi.org/10.29313/amwaluna.v2i1.3156

Algifari. Analisis Regresi Teori, Kasus, dan Solusi. Yogyakarta: BPFE, 2013. Anggraeni, Rr. Tini. Penilaian Tingkat Kesehatan Bank Syariah.

Antonio, Muhammad Syafi'I. Bank Syariah dari Teori ke Praktik. Jakarta: GEMA INSANI, 2009.

Ariyanto, Taufik, Faktor Penentu Net Interest Margin Perbankan Indonesia, Jurnal Perbanas, Vol.13 no.1 (juni 2011).

Boediono, Wayan Koster. Teori dan Aplikasi Statistika dan Probabilitas. Bandung: PT. Remaja Rosdakarya.

Cahyo, Mufti Nur. Analisis faktor-faktor yang mempengaruhi Margin Bank Umum Syariah. Semarang: Universitas Diponegoro, 2013.

Danang Sunyoto, Uji Khi Kuadrat \& Regresi untuk penelitian, (Yogyakarta: Graha Ilmu, Ed. I; Cet.I, (2010).

Dendawijaya, Lukman. Manajemen Perbankan. Bogor: Ghalia Indonesia, 2009. Hesti, Diah Aristya. Analisis pengaruh ukuran perusahaan, kecukupan modal,

Dwi Nur'aini Ihsan, Analisis Laporan Keuangan Perbankan Syariah, (Banten: UIN Jakarta Press, 2013)

Efferin Sujoko, dkk, Metode Penelitian Untuk Akuntansi, Suatu Pendekatan Praktis, (Jawa Timur: Bayu Media Publishing, Juni, 2004)

Karim, Adiwarman. Bank Islam (Analisis Fiqih dan Keuangan). Jakarta: Rajawali Pers, 2011.

Kasmir. Manajemen Perbankan. Jakarta: Rajawali Pers-Ed.Rev, 2012.

Silvia, S. A. (2017). Pengaruh Kualitas Aset Terhadap Profitabilitas Pada Perbankan Syariah Di Indonesia. AL-FALAH : Journal of Islamic Economics,

https://www.kompasiana.com/fahmiaulia/5acb93d0dd0fa848273ad632/persentasejumlah-nasabah-bank-syari-ah-di-indonesia

https://www.kompasiana.com/sitinurlaelaghofar/5e73a64c097f364fc7667ee7/bagaiman a-kondisi-perbankan-syariah-di-indonesia-saat-ini?page=all

https://www.kompasiana.com/ikayulip/572ac4d3f1927349059f6b6f/perkembanganbank-syariah-di-indonesia

https://blog.amartha.com/sejarah-dan-perkembangan-bank-syariah-di-indonesia/

https://www.cekaja.com/info/penilaian-tingkat-kesehatan-bank-umum-syariah-dan-unitusaha-syariah/ 